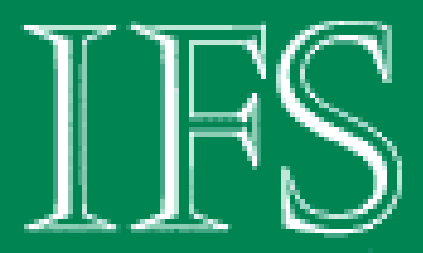

\title{
THE 'FAT TAX': \\ ECONOMIC INCENTIVES TO REDUCE OBESITY
}

Andrew Leicester Frank Windmeijer 


\title{
The 'fat tax': economic incentives to reduce obesity
}

\author{
Andrew Leicester and Frank Windmeijer"
}

Institute for Fiscal Studies

\section{Introduction}

This Briefing Note looks at the potential for the introduction of a 'fat tax' into the UK in an effort to reduce the growing prevalence of obesity in Britain. There are different forms such a tax could take. One possibility is to tax the nutrient contents of foods such that those containing more fat or salt, for example, are taxed more heavily. Alternatively, particular types of foods, such as snacks or soft drinks, could be subject to a tax, or VAT could be extended to foods that are currently zero-rated but have a high fat content.

Revenue from a 'fat tax' could be used in various ways, such as financing subsidies for healthy foods or exercise equipment, funding advertising campaigns for healthy eating or in schools. Alternatively, it could form part of general government receipts.

This Briefing Note will look at trends in UK obesity (Section 2) and examine evidence on eating habits and exercise in order to see whether trends here can account for what we see happening to obesity (Section 3). We will then go on, in Section 4, to review some of the key economic reasons behind why we might be concerned about obesity and why we might consider there to be a case for government intervention. Moving on, we discuss how food is currently taxed (Section 5) and the various ways in which a 'fat tax' might be introduced (Section 6), looking at particular issues the government might need to address should it wish to introduce one. We will finish in Section 7 by presenting some simple analysis of a hypothetical 'fat tax' in terms of how it might impact differently on the rich and the poor. Section 8 concludes.

\section{Trends in obesity}

Officially, a person is obese if they have a body mass index (BMI) of 30 or more. The BMI is taken as the ratio of weight in kilograms to height in metres squared. Someone with a BMI above 40 is categorised as 'morbidly obese',

\footnotetext{
* Address for correspondence: andrew_1@ifs.org.uk, frank_w@ifs.org.uk; IFS, 7 Ridgmount Street, London, WC1E 7AE; 020-7291 4800.

Financial support from the ESRC Centre for Microeconomic Analysis of Public Policy is gratefully acknowledged. The authors would like to thank Jane Landon and Paul Lincoln at the National Heart Forum, Robert Chote at IFS and Jerome Adda at UCL for invaluable advice and comments in the preparation of this paper, Paola Primatesta at UCL Medical School for providing useful data and Ian Crawford at IFS for carrying out the calculations for Section 7. All errors and omissions remain their own.
} 
where health problems associated with obesity become even more severe. A 'healthy' BMI is taken to be one in the range 20-25. People with a BMI of 2530 are classed as 'overweight'. Figure 1 summarises the BMI classifications.

Figure 1. Body mass index (BMI) classifications

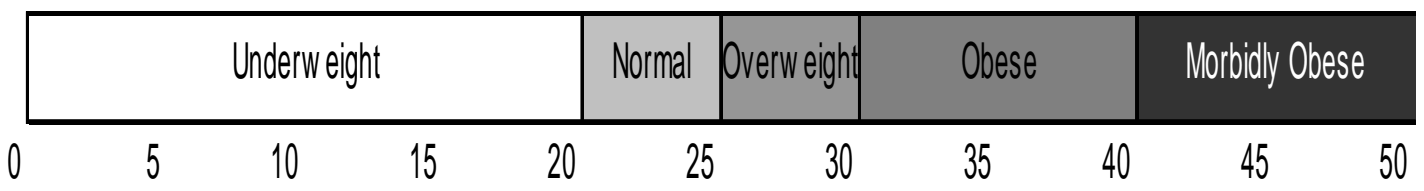

Using this BMI definition, the regular Health Survey for England, published by the Department of Health since 1993, shows how the trend in obesity has been upwards over the last decade. ${ }^{1}$ These results are shown for men and women in Figures 2 and 3. Earlier evidence ${ }^{2}$ suggests that this trend has continued for some time - the percentage of men with a BMI of 25 or more was $45 \%$ in 1986-87 compared with 64\% in 2002; for women, the increase was from $36 \%$ to $58 \%$. Over the last decade, the proportion of men and women classified as overweight has stabilised but the percentage deemed obese or morbidly so has continued to rise - from $13 \%$ in 1993 to $21 \%$ in 2002 amongst men, and from $16 \%$ to $26 \%$ amongst women. Whilst obesity - particularly morbid obesity - is slightly higher amongst women, more men than women tend to be 'overweight'. Interestingly, the proportion of men above recommended BMI fell between 2001 and 2002, whilst the proportion for women rose quite substantially.

Figure 2. Percentage of English men aged 16-64 classified overweight, obese or morbidly obese

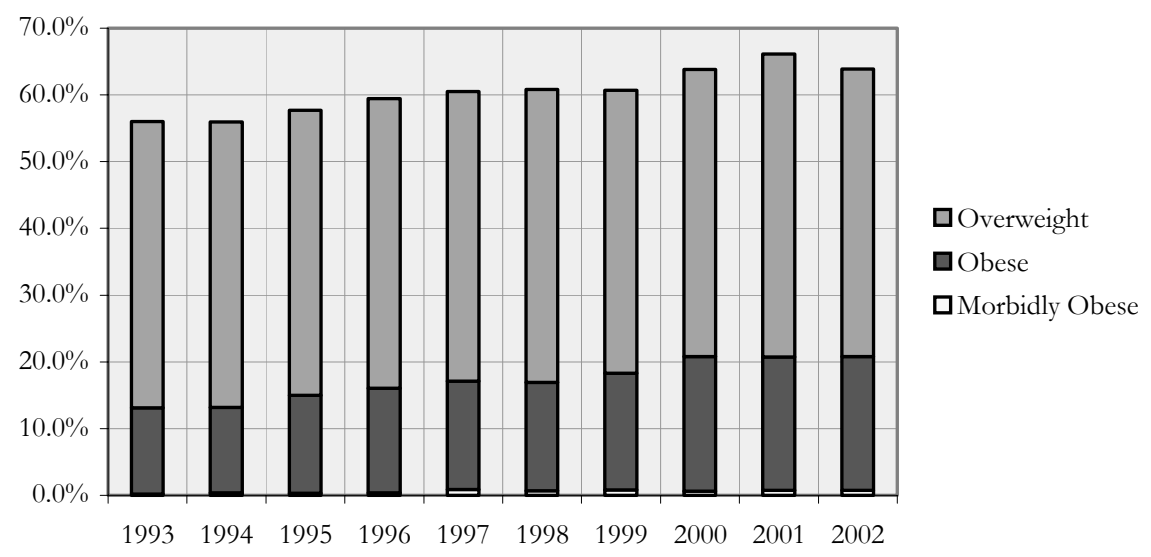

Source: Health Survey for England, various years.

\footnotetext{
${ }^{1}$ See http://www.dh.gov.uk/assetRoot/04/06/60/70/04066070.xls for raw figures. Note that the figures in that table cover the population aged 16 and over. For consistency with the earlier data from 1986-87, we calculated figures for ages 16-64 only.

${ }^{2}$ British Heart Foundation, 2003.
} 
Figure 3. Percentage of English women aged 16-64 classified overweight, obese or morbidly obese

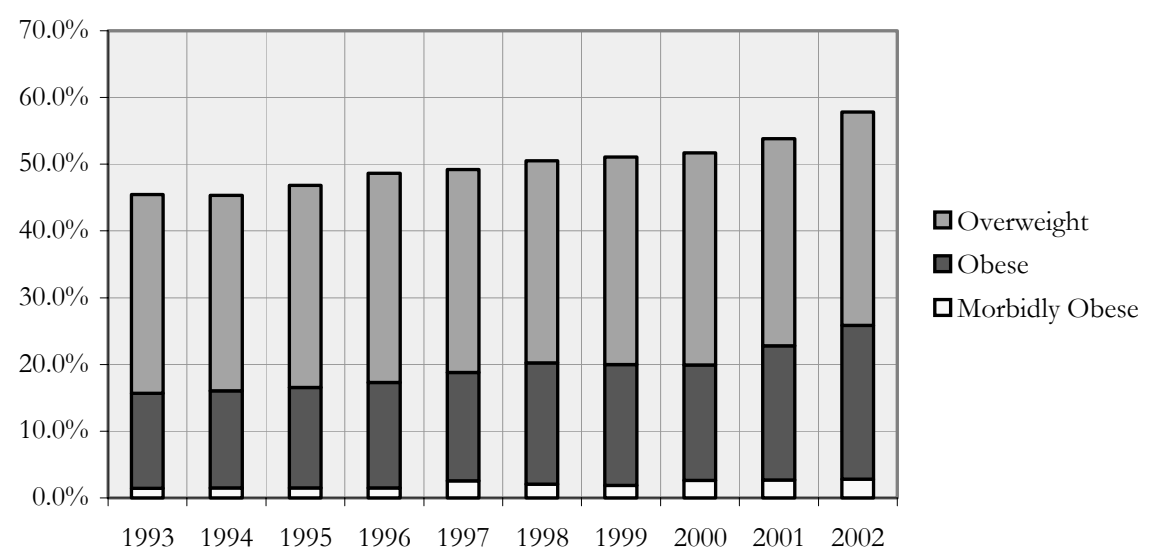

Source: Health Survey for England, various years.

\section{Why might obesity have risen?}

Higher average weights may be a result of higher overall energy intake, lower energy expenditure or some combination of the two. If energy intake has increased, it may not be due to people eating more frequently throughout the day - it may instead be due to a higher intake of calories at each meal, perhaps through eating different types of food. Alternatively, people may be eating more between meals. Declining energy use may be due to people having more sedentary jobs or to less physical exercise being taken. Evidence from the $\mathrm{USA}^{3}{ }^{3}$ where the percentage of adults overweight or obese has risen from around $45 \%$ in the early 1960 s to more than $60 \%$ in 1999 , suggests that the main source of this rise has been an increase in energy intake between meals. Average energy expenditure has not declined since the 1960s and average consumption per meal has also remained unchanged, but total energy intake has risen. This might suggest a role for a discretionary 'fat tax' on snack foods and drinks.

For the UK, various sources of evidence on energy intake are available. One is the National Food Survey (NFS), which records the nutritional values of food purchased rather than food consumed. From these data, total energy purchases per person per day fell from 2,290 kcal to just 1,750 kcal between 1975 and 2000, a fall of $23.6 \% .^{4}$ Further, around $42 \%$ of total calorie purchases in 1975 came from fat, compared with $38 \%$ in 2000. The Department of Health Committee on Medical Aspects of Food and Nutrition Policy (COMA) has a target of 33\% energy from fat. The observed fall seems hard to reconcile with

\footnotetext{
${ }^{3}$ Cutler, Glaeser and Shapiro, 2003.

${ }^{4}$ Note that the Recommended Daily Allowance (RDA) for calories even for women is 2,000, substantially above this figure. Figures come from British Heart Foundation (2003), based on NFS data.
} 
the increased overweight figures seen in this country, as do trends in more disaggregated expenditures on particular types of food, reported in Figure 4. 'Good' foods - fruit and vegetables - appear in the left-hand graph, whilst 'bads' - fat, salt and sugar - appear in the right-hand one. The graphs are drawn using the same scale for ease of comparison.

Figure 4. Purchase of various food types, 1942-2000
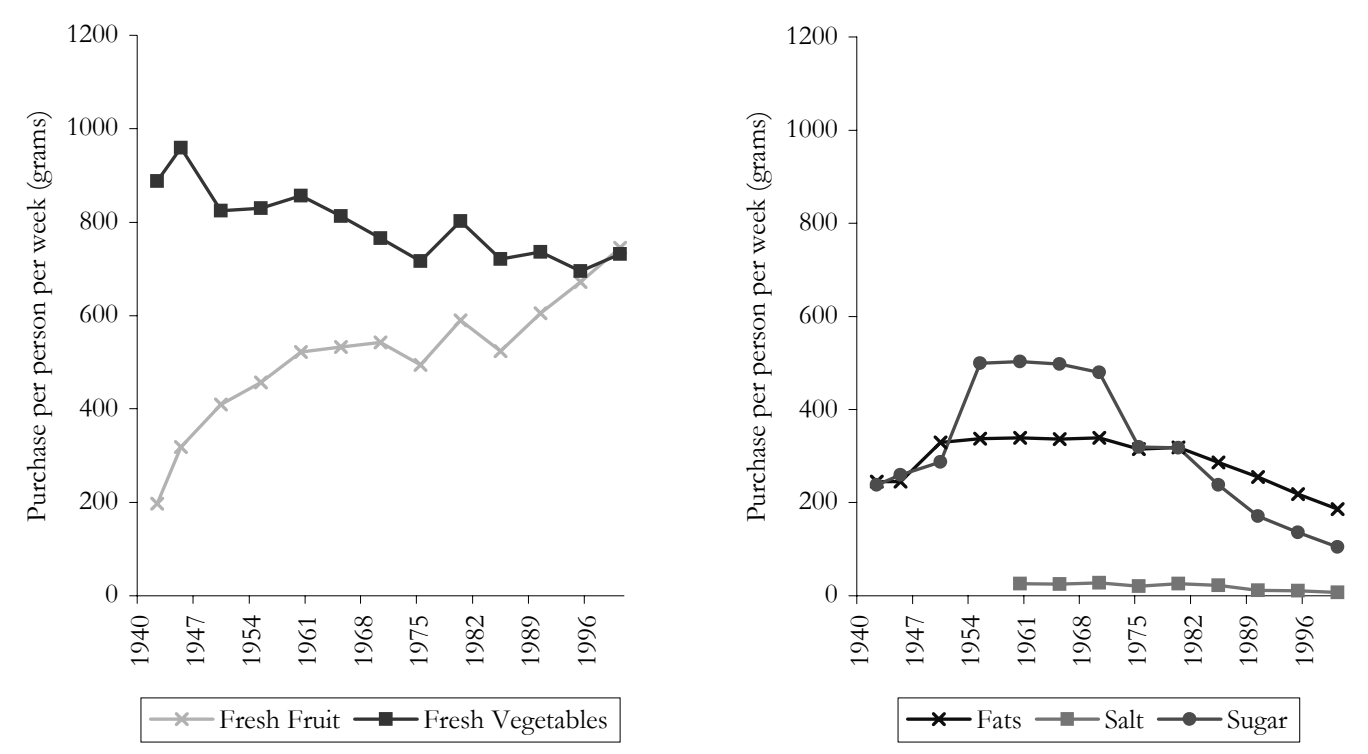

Source: British Heart Foundation, 2003.

Total purchase of fats (butter, margarine, etc.) was some $245 \mathrm{~g} /$ week per person in 1942 , rising to $339 \mathrm{~g} /$ week in 1970 before declining again to just $186 \mathrm{~g} /$ week in 2000. Purchases of (table) salt fell from 28g/week per person in 1970 to $7 \mathrm{~g} /$ week in 2000 , whilst sugar purchases peaked at $503 \mathrm{~g} /$ week per person in 1960 before falling back to just 105g/week in 2000. Each of these 'bads' seems to have declined markedly, particularly since the 1980s. Meanwhile, fresh fruit purchases rose from just $197 \mathrm{~g} /$ week per person in 1942, to $543 \mathrm{~g} /$ week in 1970 and $745 \mathrm{~g} /$ week in 2000 . Fresh vegetable purchases ${ }^{5}$ rose from $717 \mathrm{~g} /$ week per person in 1975 to $732 \mathrm{~g} /$ week in 2000 (though this is far below the 1945 peak of $959 \mathrm{~g} /$ week). In total, however, fruit and vegetable purchases have been increasing steadily since the mid-1980s, to reach a new peak in 2000. In short, these trends appear difficult to reconcile with a substantial and continuing rise in obesity.

The National Audit Office (2001) points out that the NFS is limited in what it includes in its measure of total energy, which could explain why it seems not to fit the obesity pattern. It does not provide full coverage of food prepared outside the home, and it excludes alcohol, soft drinks and confectionery eaten at home. The NAO suggests that such excluded foods could add $20 \%$ to the

\footnotetext{
${ }^{5}$ Excluding potatoes.
} 
total recorded figures, and this share is likely to increase as spending on food prepared outside the home - such as takeaway meals and snacks and restaurant meals (collectively 'catering') - increases relative to food prepared at home. Evidence from the Family Expenditure Survey shows how spending on food prepared outside the home has risen in recent years. In 1975, an average of $24.6 \%$ of total household spending went on food prepared in the home and $4.1 \%$ on catering. By 1999, these figures had become $14.8 \%$ and $6.5 \%$ respectively. ${ }^{6}$

Evidence from other surveys backs up the point that the NFS may fail to capture total energy intakes properly. In 1986-87, the Dietary and Nutritional Survey of British Adults ${ }^{7}$ was carried out, and this was followed by the National Diet and Nutrition Survey in 2000-01. ${ }^{8}$ These surveys recorded actual intakes of energy rather than converting spending to intakes, and included food prepared outside the home. They suggested that the average daily energy intake for people aged 16-64 in 1986-87 was around 2,460 kcal for men and 1,685 $\mathrm{kcal}$ for women. By the 2000-01 survey, these figures had fallen to 2,325 kcal for men and 1,640 kcal for women. ${ }^{9}$ This gives falls of around $5.5 \%$ for men and $2.7 \%$ for women, far smaller than the drops recorded in the NFS. For men, the percentage of total energy from fat fell from $40.4 \%$ to $35.8 \%$ between the surveys; for women, the decline was from $40.3 \%$ to $35.9 \%$.

Trends in energy expenditure are hard to find. British Heart Foundation (2003) presents figures on the percentage of people engaged in three levels of physical activity:

- low - less than 30 minutes of physical activity on one day per week;

- medium - 30 minutes of physical activity on between one and four days per week;

- high - 30 minutes of physical activity on at least five days per week.

Amongst the population aged over 16, it finds that whilst the percentage of men reporting high activity remained unchanged between 1994 and 1998 at 37\%, the share of low-activity men rose from $30 \%$ to $35 \%$. Amongst women, there was a small increase in the high-activity population from $22 \%$ to $25 \%$, but a larger rise, from $35 \%$ to $41 \%$, in those reporting low exercise. It would appear that doing less exercise may be a factor behind the rise in obesity, but in the absence of longer-term trends, it is hard to be sure.

One fear might be that if there is a trend towards declining physical activity, it is likely to continue if children are not encouraged to undertake regular

\footnotetext{
${ }^{6}$ Source: Blow, Leicester and Oldfield, 2004.

${ }^{7}$ Gregory et al., 1990.

${ }^{8}$ http://www.foodstandards.gov.uk/multimedia/pdfs/ndnsv2.pdf.

9 Figures in the survey are reported in megajoules (MJ) to one decimal place; the calorie values are to the nearest equivalent $5 \mathrm{kcal}$. The decline for men's energy intake was statistically significant; that for women's was not.
} 
exercise. Some evidence from the Department for Transport (2003) suggests this might be the case, with the percentage of children aged 5-16 walking or cycling to school falling from 59\% in 1989-91 to 50\% in 1999-2001.

There is other incidental evidence on changing physical activity habits. The National Audit Office (2001) argues that the average person spent 13 hours per week watching television in the 1960s, and 26 hours per week doing so in the 1990s. However, without knowing what activity this additional television time has replaced, we cannot be sure of its effects on weight - it could be that a large amount of the increase has come at the expense of other sedentary hobbies or even sleeping time. Prentice and Jebb (1995) use the evidence on television-viewing, along with figures showing increasing car ownership per household and one-year survey data suggesting that overall activity rates were low, to suggest that

it seems reasonable to conclude that the low levels of physical activity now prevalent in Britain must play an important, perhaps dominant, role in the development of obesity by greatly reducing energy needs.

However, without better time-series evidence on changing physical activity rates, this must remain at best an informed assumption about the role of energy expenditure in the increase in obesity rates.

Further survey evidence is available. The British Household Panel Survey (BHPS) follows a sample of around 7,000 households over time, asking them various questions about their incomes and life. In three years - 1996, 1998 and 2000 - participants were asked the following question: 'How often do you play sport or go walking or swimming?'. Respondents could choose from 'At least once a week', 'At least once a month', 'Several times a year', 'Once a year or less' or 'Never/almost never' as answers. Whilst the percentage of people reporting such activity at least once a week remained fairly steady each time at around $52-54 \%$, the percentage answering 'Never/almost never' rose from $19.7 \%$ in 1996 to $23.2 \%$ in 2000 .

Overall, therefore, the data on physical activity seem to support the idea that there has been a decline in people's actual participation over time. However, more detailed information would be useful.

\section{Why is obesity of economic concern?}

Obesity imposes costs not only on those who become obese but also on the rest of society. These costs include medical costs for treating obesity and its resultant illnesses, lost working days and so on. Since people do not consider these costs when making their diet and exercise decisions, obesity rates will tend to be higher than those that would occur if these costs were taken into account. Economists can then think of using economic instruments, such as a 
'fat tax', to affect people's decision-making in order to bring the outcome closer to the socially desirable one.

The National Audit Office (2001) presents some estimated financial and economic costs of obesity in Britain in terms of sick days from work.

- In 1998, 9,000 people died prematurely before retirement age as a result of obesity, resulting in 40,000 lost working years. ${ }^{10}$

- More than 18,000,000 working days were lost in 1998 either due directly to obesity (largely people taking time off to consult GPs about their weight) or due to secondary illnesses.

- The estimated costs of premature death and sickness are $£ 2.1$ billion in 1998 and $£ 3.6$ billion for 2010 . $^{11}$

- The estimated costs of treating obesity and its consequent illnesses in England in 1998 were $£ 479.4$ million, or $1.5 \%$ of NHS spending. This is a conservative estimate.

- The estimated number of deaths in England in 1998 directly attributable to obesity was 30,000 (6\% of deaths). The total number of lost years of life from premature death was 275,000 .

\section{Current 'fat taxes' in the UK and around the world}

There is no such thing as an explicit 'fat tax' currently operating in the UK, though taxation of food is not uniform. Food is VAT zero-rated in the UK, but there are some exceptions that attract standard-rate VAT of $17.5 \%{ }^{12}$ All food provided as catering, takeaway or in restaurants is standard-rated. Other standard-rated food items would be likely to attract a tax premium were an explicit 'fat tax' to be introduced, whether on groups of goods such as snack products or on fat content. These include confectionery, ice cream and crisps. However, some items that would be likely to be highly taxed based on fat content, such as butter and cakes, do not attract VAT. Similarly, some goods do attract VAT that would not attract a 'fat tax', such as mineral water, rice cakes and fruit juices. Thus there is no way we can consider the VAT system on food in the UK as anything like a 'fat tax'. Do any other countries have anything more akin to what we were talking about in Section 1 ?

Some countries have similar rules to the UK, applying sales tax to particular items but not others without doing so in such a way as to be able to think of it as a 'fat tax'. Thus in France, sweets, chocolates, margarine and vegetable fat attract VAT of $20.6 \%$ whilst other foods attract VAT of only $5.5 \%$. In Canada, sales tax applies to soft drinks, sweets and snack foods but other foods are free from sales tax. Similarly, in the USA, various states have sales taxes on soft

\footnotetext{
${ }^{10}$ This assumes everyone retires at state retirement age and not before.

${ }^{11}$ Of course, in strictly numerical terms, there are savings from premature deaths in terms of lower public pension provision, for example.

${ }^{12}$ For details, see http://www.hmce.gov.uk/forms/notices/701-14.htm.
} 
drinks, snack foods and sweets. However, none of these taxes is designed explicitly as a 'fat tax'. What is clear, however, is that the practice of taxing certain types of foods more highly than others is well-established, and often it is foods and drinks considered to be particularly unhealthy that are taxed more heavily. Any explicit 'fat tax' on these foods would, in many cases, be in addition to VAT. There are no examples around the world of foods being directly taxed according to their fat or other nutritional content, however.

Whilst there is no 'fat tax' operating in the world at the moment, the idea is under active consideration in Ireland, where around $60 \%$ of people are overweight or obese. ${ }^{13}$ The UK government is due to publish a White Paper looking at obesity, amongst other issues, in Summer 2004; however, there are no indications that this will include proposals for a 'fat tax', ${ }^{14}$ although recent reports suggest that the Prime Minister's Policy Unit has actively considered the idea. ${ }^{15}$

\section{Implementing a 'fat tax'}

There are various ways in which a 'fat tax' could be introduced. As discussed above, it would be possible to extend VAT to cover those foods that are currently exempt but that have a high fat content, such as butter, whole milk and plain biscuits. Of course, this may not be an explicit 'fat tax' as suggested earlier, even if it were made clear that the reason VAT was being extended to cover these additional items was to encourage healthier eating. This method was suggested by Marshall (2000), who argued that VAT should be extended to cover the main sources of saturated fat in the UK diet - whole milk, butter, cheese, biscuits and cakes. He suggested that such a move could reduce the number of premature deaths per year by between 900 and 1,000. An alternative would be to introduce an additional tax on a whole variety of foods which could be more explicitly marketed as a 'fat tax'. This could be done in two ways: either particular food types could be subject to the tax according to their fat or other nutrient content, or foods could be taxed according to the percentage of fat they contain. Jacobson and Brownell (2000) argue that the former option is more likely, since

\footnotetext{
legislative bodies find it more practical to tax well-recognised categories of food that play little useful role in nutrition. Soft drinks and snack foods typically add unneeded calories to the diet or replace nutritious foods, such as low-fat milk or fruit, without providing significant levels of nutrients.
}

There would be considerable difficulty in implementing a 'fat tax' according to fat content in food. Some fat is important in the diet - ideally, we would like to tax overconsumption of fat, but this would clearly be a practical impossibility.

\footnotetext{
${ }^{13}$ Meikle, 2003.

${ }^{14}$ Batty, 2004.

${ }^{15}$ See, for example, the BBC, http://news.bbc.co.uk/1/hi/health/3502053.stm.
} 
Some foods, such as butter, are almost entirely fat and so would attract very high taxes by their very nature. Further, there may need to be frequent reevaluation of the tax rates in order to generate the desired effects, which could be costly, as would be the costs of monitoring the impact of any 'fat tax' scheme (based on fat content or otherwise). Manufacturers may also frequently change their production processes, causing the fat content of foods to change, which may lead to prices having to be altered regularly. However, if a tax could be brought in on this basis, is there a rationale for focusing on fat in particular, as opposed to salt or other 'bad' nutritional components of the food? The National Audit Office (2001) suggests that

\footnotetext{
Fat has a higher energy density than other components, and fatty foods tend not to satiate the appetite as quickly as foods that are high in carbohydrates. Exposure to high-fat foods is thought to be largely responsible for the 'over-eating effect', also known as 'passive over-consumption' where the appetite fails to regulate adequately the amount of energy consumed.
}

This suggests that fat in particular is the key nutrient in terms of obesity. However, weight depends upon lifetime energy consumption relative to lifetime energy expenditure, so any tax that focused solely on fat or other particular nutrients may be rather a blunt instrument with which to tackle obesity. This could suggest a 'calorie tax' as an alternative.

Another problem with taxing fat content may be that it would limit the price differentials between 'high-' and 'low-'fat varieties of food - such as whole milk versus semi-skimmed and skimmed milk - since the latter varieties would also attract some tax. If, instead, the government chose simply to tax whole milk, the differential would be greater.

Given the practical difficulties there may be with a tax on nutrients, a more likely approach would be to take certain food groups, such as crisps, snacks and soft drinks, and apply a tax (either as a flat rate or as a percentage of the retail price). Such a tax could be overtly introduced as a tax on the foods' 'unhealthiness' and an attempt to introduce a greater price differential between such foods and healthier alternatives such as fresh fruit or juices or lower-sugar cereals. Naturally, the obvious problem with taxing food groups is deciding which goods would face the tax and which would be exempt, and it is likely that there would be fierce lobbying by the food industry and manufacturers and conflicting advice.

There is some experimental evidence in the USA that introducing greater price differentials may cause people to change their consumption behaviour. French et al. (1997) looked at vending machines that sold both low-fat and regular snacks in nine sites. They observed sales from the machines before the experiment, and then reduced the price of the low-fat goods by $50 \%$ for three weeks. After that, the prices returned to their old levels, and sales were observed again. The authors found that during the trial, whilst total snack sales 
did not change, the percentage of total sales that were low-fat goods rose from $25.7 \%$ to $45.8 \%$, but afterwards, the percentage fell back again to $22.8 \%$, suggesting that it was the price that was the key factor.

Of course, this evidence is only suggestive - it was conducted in the USA and we do not know that British consumers would react in a similar way. The vending machine gives a particular mode of sale which presents consumers with full-fat and low-fat alternatives very explicitly along with prices, but it is not clear that the same results would occur in a supermarket setting, for example, where people may seek out what they want without really considering alternatives. This experiment also saw the prices of low-fat goods reduced rather than the prices of high-fat goods increased, which may have different psychological effects on the decision to switch between high- and low-fat products, or a different income effect.

There may be concerns that any 'fat tax', however designed, would be subject to legal challenge under EU or WTO rules. It is not clear that this would be the case, however. We could view a 'fat tax' as a 'sin tax' similar to alcohol taxation, and no challenge has been brought against those taxes. The same applies to other small taxes in other countries, such as the Irish tax on plastic shopping bags. Were a 'fat tax' to be implemented as an extension of VAT, the EU would not view it negatively since there are only rules governing the reduction of VAT, not its application to new goods. Bringing more goods into the scope of VAT would, of course, be politically sensitive, as the arguments over domestic fuel in Britain in the early 1990s proved, but it would certainly be legislatively possible to change the VAT structure in this way.

How funds from any 'fat tax' should be used could be another area of contention. In the USA, most of the state taxes on snacks or soft drinks are simply part of overall tax revenue - that is, the revenue is not explicitly used to fund counter-obesity measures. Alternatively, the funds could be hypothecated, i.e. earmarked for particular forms of expenditure. Revenues from the London Congestion Charge are hypothecated for transport, for example. Funds from a 'fat tax' could be used to finance healthy eating advice in schools or on television, for the NHS, etc. Alternatively, the income could be used to reduce other taxes or provide subsidies on healthy foods or exercise equipment.

There will be problems however a 'fat tax' is implemented. Some people will be affected in what would be seen as an unfair manner - for example, should mothers buying full-fat milk for their children on government advice ${ }^{16}$ be affected? Of course, if a tax were implemented on snack foods and soft drinks,

16

http://www.foodstandards.gov.uk/healthiereating/asktheexpert/childbabies/childrenandmilkq: 'Children under two years old need full-fat milk because it gives them the extra calories and vitamin A that a younger child needs. Children between the ages of one and three need to consume an average of $350 \mathrm{mg}$ of calcium a day. About $300 \mathrm{ml}$ full-fat milk (three fifths of a pint) would provide this.' 
milk would be unlikely to be affected, but if full-fat milk were increased in price to encourage a switch to lower-fat milk, it may be possible to provide vouchers to mothers of young children to enable them to obtain it at the lower, pre-tax price. This would be costly to implement and enforce.

The effect of any 'fat tax' on the British food industry would be an important consideration before its implementation, and the response of manufacturers and retailers to it would be a key determinant of its success. A possible danger of introducing a tax on particular foods is that the price of other foods may rise as well, increasing profits at the cost of eliminating the desired price differentials. Alternatively, manufacturers may have greater incentives to change production processes to reduce fat content in order to reduce the tax liability their products would face.

One possible argument in favour of the tax is that consumers are unlikely to try to avoid it by sourcing their food from abroad, since much food is perishable and transportation costs would certainly outweigh the scale of a likely 'fat tax'.

However a 'fat tax' is implemented, its success at reducing obesity will depend on the extent to which it encourages people to reduce consumption of fatty food, and the extent to which fatty foods and snacks have contributed to the rise in obesity. We discussed some evidence on this latter point in Section 3. What evidence is there on the responsiveness of the demand for foods, and fatty foods in particular, to their prices?

The way in which demand changes as a result of price changes is known as the price elasticity of demand. This is calculated as the percentage change in the quantity demanded divided by the percentage change in the price. Since demand falls as prices rise, price elasticities are negative. The greater the elasticity (i.e. the more negative it is), the smaller the increase in price needed to reduce consumption by a target amount. For example, if we wanted to reduce consumption of butter by $10 \%$ and its elasticity were -1.0 , it would require a $10 \%$ increase in price to do so, but if its elasticity were -2.0 , it would require only a $5 \%$ increase.

Marshall (2000) based his argument that VAT on whole milk, cheese, butter, etc. could reduce premature deaths by between 900 and 1,000 per year by making plausible assumptions about their price elasticities. For example, he argued that whole milk had an elasticity of -1.0 since it has close substitutes in the form of skimmed and semi-skimmed milk, whereas cheese (estimated elasticity -0.5$)$ and butter $(-0.7)$ have fewer direct substitutes and so lower elasticities. If these assumptions are overestimates, the likely impact of his proposal would be smaller. Recent UK evidence from the National Food Survey $(2000)^{17}$ looks at estimated price elasticities of demand for various aggregated food groups over the period 1988 to 2000. The estimated own-price

\footnotetext{
${ }^{17}$ Lechene, 2000.
} 
elasticity for cheese is -0.35 , though Marshall's assumed -0.5 is within the $90 \%$ confidence interval for this estimate. There is no specific estimate of the elasticity for butter, though that for fats in general is -0.75 , similar to Marshall's assumed value. There are no estimates for buns, cakes, biscuits or desserts, so the accuracy of Marshall's estimates here cannot be corroborated. The only estimate for milk is a general one of -0.36 rather than a specific one for whole milk, though the demand for whole milk is clearly likely to be more elastic since there are close substitutes in the form of semi-skimmed and skimmed varieties.

\section{Simulation: the distributional effects of a 'fat tax' when behaviour does not change}

We have simulated a 'fat tax' proceeding along the 'taxing the nutritional content' approach. In our modelled tax, we take four 'bad' nutrients commonly found in various foodstuffs and apply a specific tax on the amount of each nutrient in each food. Our data come from the National Food Survey (2000), which records spending on different foodstuffs by around 8,000 households. Each food can then be broken down by its nutritional content to establish the total amount of various nutrients eaten by each household over the one-week sample period. By comparing the pre- and post-tax expenditures on food by each household, we can work out how much this hypothesised 'fat tax' would cost, and thus what percentage of total income each household would lose through its introduction. By showing how this loss varies across the income distribution, we can get some idea of how the 'fat tax' could differentially affect poor and rich households.

Note that unlike Marshall (2000), we do not include any behavioural responses in these calculations. These results should therefore be taken as indicating upper bounds on the likely tax burdens at each point in the income distribution (since the anticipated response would be the reduction of consumption of taxed goods which would thereby reduce the incidence of the tax). When looking at the results that follow, it is important to bear in mind the limiting nature of the data used to derive them; as discussed in Section 3, the NFS does not record food prepared outside the home, confectionery (a good likely to attract a significant 'fat tax' as a share of retail value), alcohol or soft drinks. These goods are highly unlikely to be consumed uniformly across the income distribution, ${ }^{18}$ and including them may give a slightly different result. The main result - that the 'fat tax' would be essentially regressive - would almost certainly continue to hold even if they were included, because other data-sets

\footnotetext{
${ }^{18}$ Blow, Leicester and Oldfield (2004) show that the percentage of total spending devoted to alcohol and to catering have inverted-U shapes across the expenditure distribution (which closely matches the income distribution). That is, rich and poor households tend to spend a small proportion of total expenditure on these goods, whereas middle-income households spend a greater share.
} 
(such as the Family Expenditure Survey) indicate that the proportion of household budgets allocated to all foods tends to decline with income.

Our simulation introduced taxes as follows:

- $1 \mathrm{p} /$ kilogram on saturated fat;

- $1 \mathrm{p} /$ kilogram on monounsaturated fat;

- $1 \mathrm{p} /$ gram on sodium (obtained from salt);

- $1 \mathrm{p} /$ gram on cholesterol.

Figure 5. Daily purchase of saturated fat across the income distribution

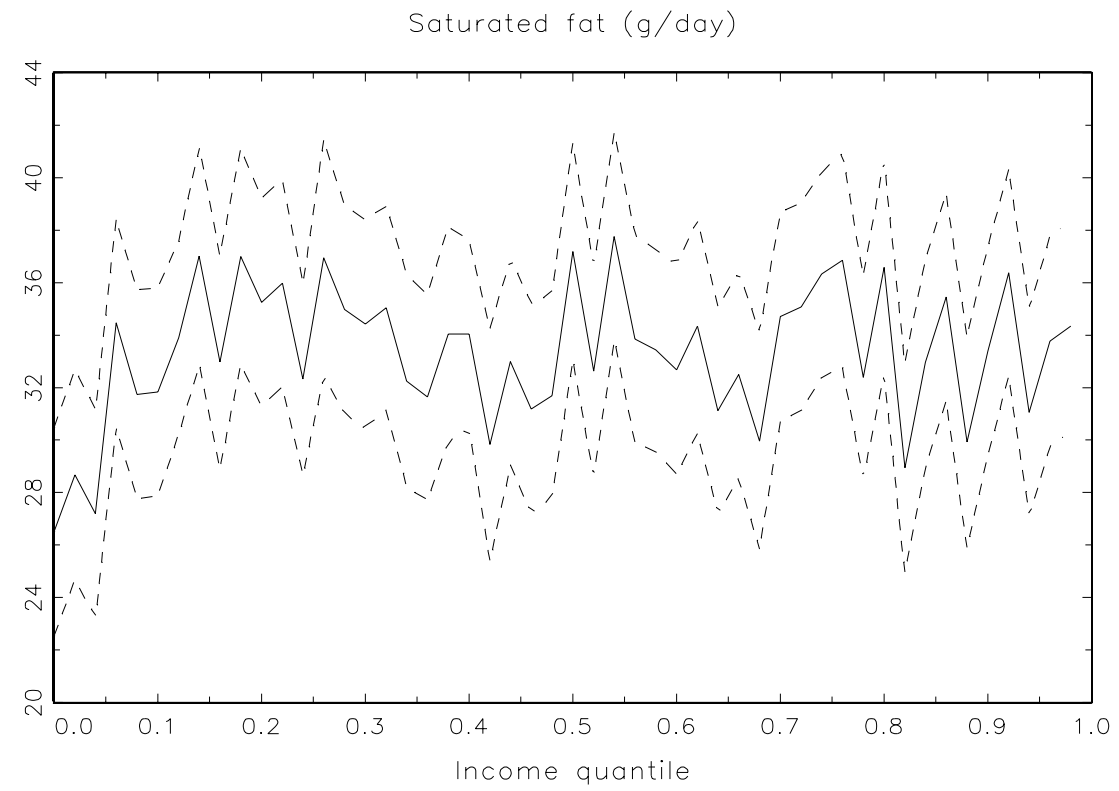

Source: Authors' calculations from the National Food Survey.

Figure 6. Daily purchase of monounsaturated fat across the income distribution

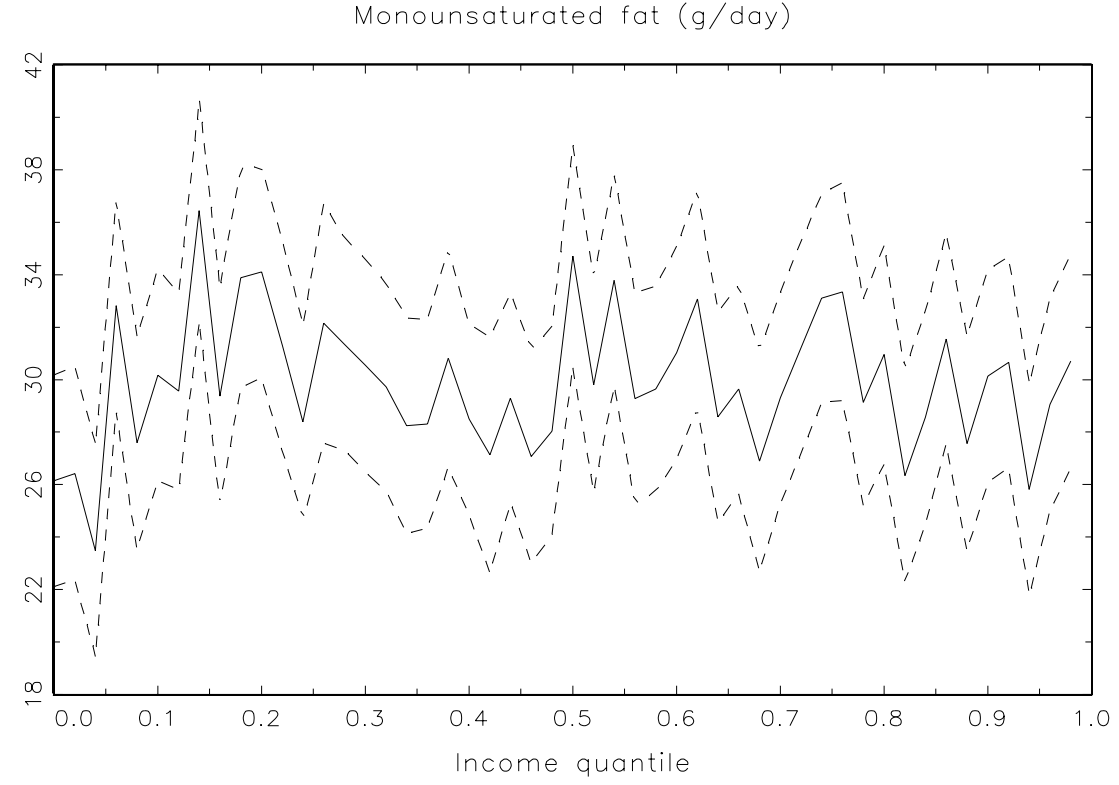

Source: Authors' calculations from the National Food Survey. 
Figure 7. Daily purchase of sodium across the income distribution

Sodium (mg/day)

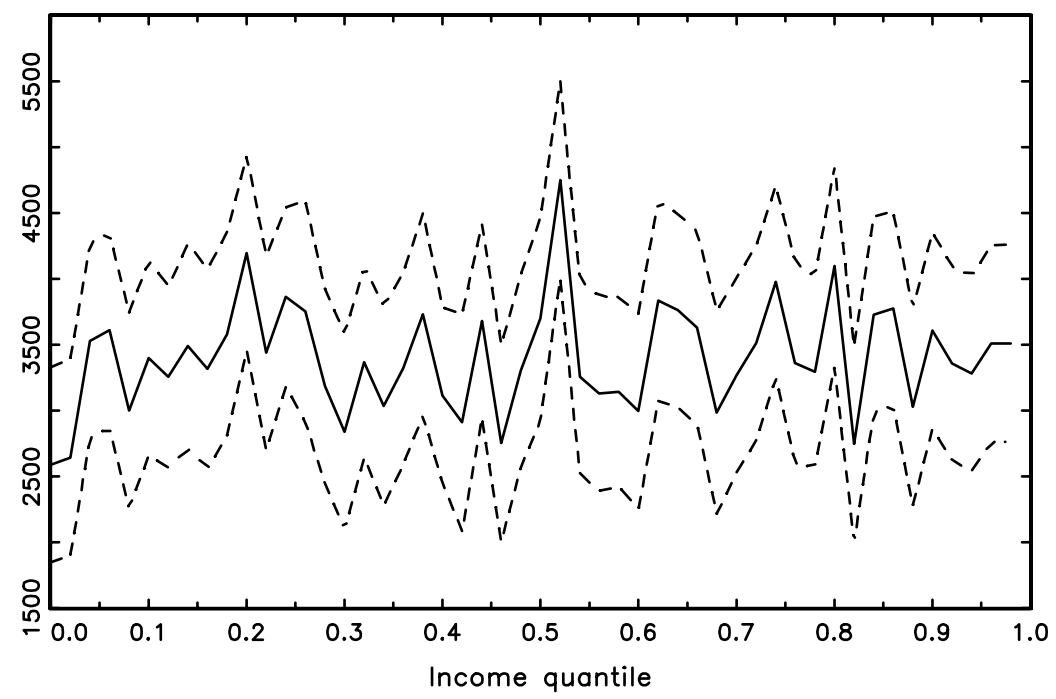

Source: Authors' calculations from the National Food Survey.

Figure 8. Daily purchase of cholesterol across the income distribution Cholesterol (mg/day)

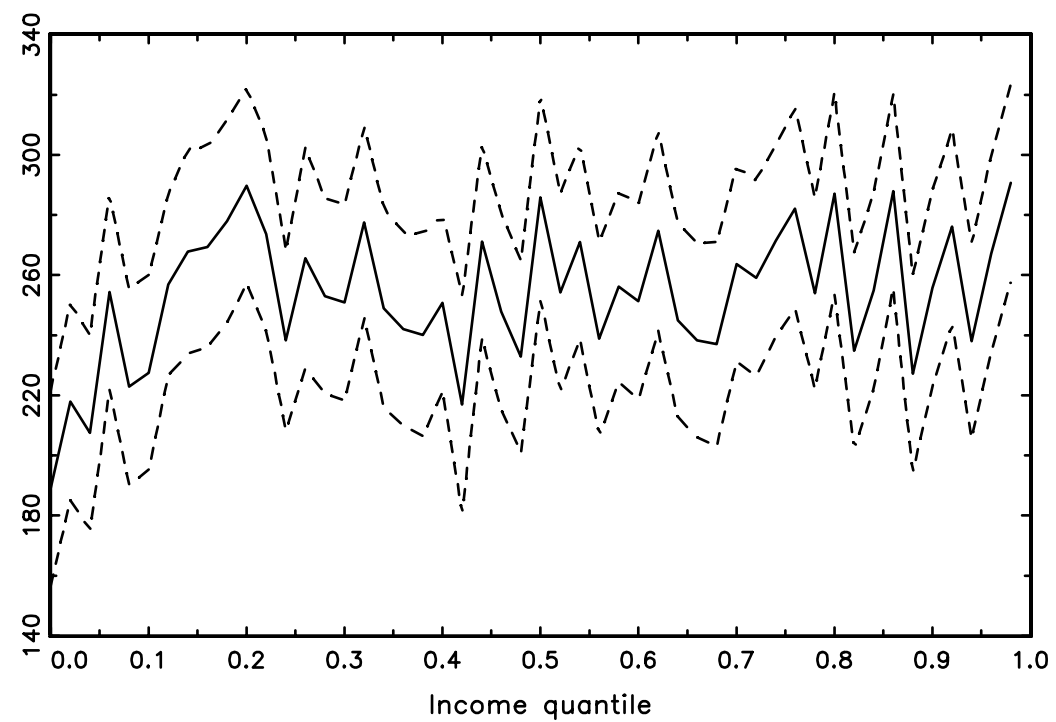

Source: Authors' calculations from the National Food Survey.

Figures 5-8 show how purchases of these four nutrients (derived from purchases of different foods in the National Food Survey) vary across the income distribution. The horizontal axis in each graph shows the income. Imagine that we line everyone up from poorest to richest and divide them into 50 equal-sized groups. The left-most point on each graph represents the average purchase of the nutrient by each household in the first (poorest) group; as we move along to the right, we look at ever-richer households, until the point on the far right represents the average amount purchased by the richest 
$2 \%$ of households. The dotted lines show $95 \%$ confidence intervals around the solid line.

What is clear from these graphs is that the amount of these nutrients purchased changes very little between rich and poor. On average, the richest people consume roughly the same amount of fat, sodium and cholesterol each day as the poorest people and those in the middle of the income distribution. The very poorest perhaps consume slightly less fat and cholesterol, but they also have particularly low incomes such that even a small tax would constitute a fairly high average tax rate.

Figure 9. Distributional effects of a 'fat tax'

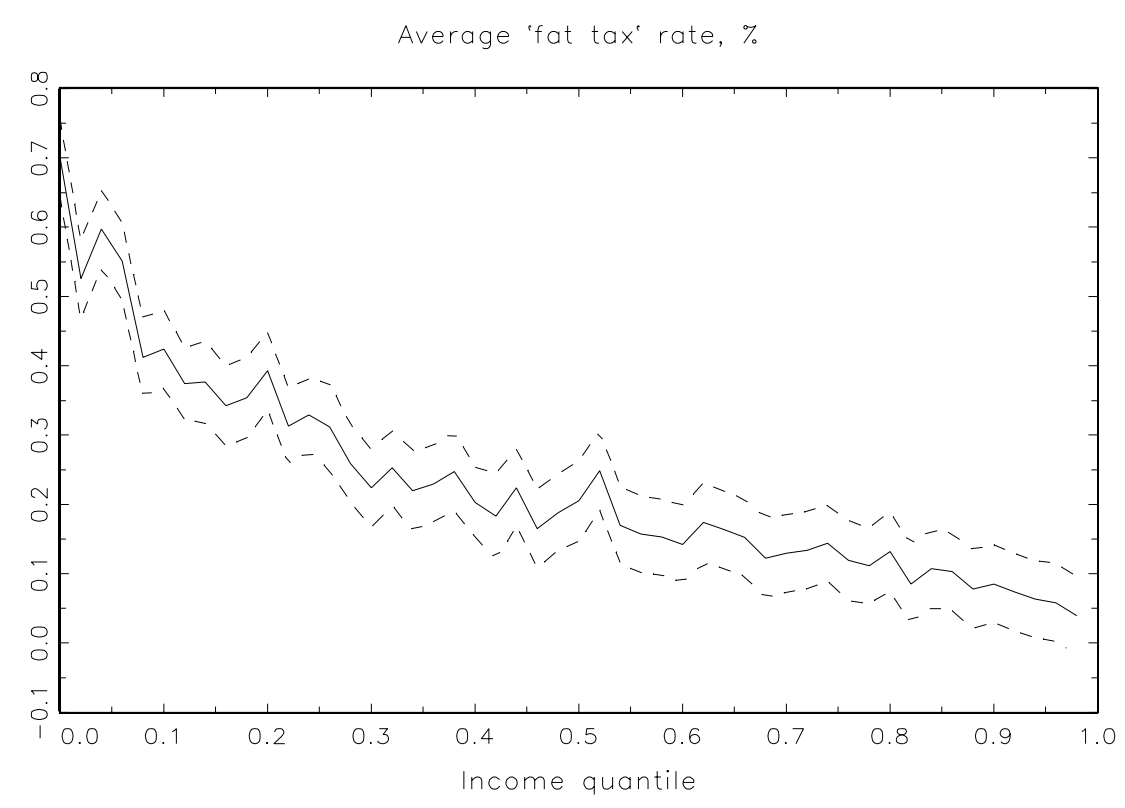

Source: Authors' calculations from the National Food Survey.

According to our analysis, the distributional effects of a 'fat tax' as set out above would be as shown in Figure 9. Again, we present 95\% confidence intervals around our point estimates. We can see that, on average, the burden would be small, but that poorer people would pay a greater share of their total income than richer people. The very poorest $2 \%$ (people with incomes of less than $£ 36$ a week) would see about $0.7 \%$ of their total income spent on the "fat tax', whilst the very richest (with incomes above $£ 519$ a week) would pay less than $0.1 \%$ of their income. People in the middle of the income distribution (with incomes of around $£ 140$ a week) would pay about $1 / 4 \%$ of their total income. Since we do not differentiate the level of tax according to income such that the rich pay a greater tax per unit of nutrient (indeed, such a system would be impossible as we would have to means-test people every time they went shopping!), the only way in which the poor would face a smaller tax burden as a share of their total income would be if they consumed significantly less fat, sodium or cholesterol. Since this is not the case (at least for the foods captured 
in the NFS), a 'fat tax' would be regressive. This is likely to be the case for any tax on food, on which the poor spend a greater share of total income than do the rich.

As a final piece of evidence, recall from Section 3 that weight gain is not triggered by consumption of fat in and of itself; it is an excess of energy intake over output that causes weight to rise. Fat is a good source of energy such that high-fat foods contain a large number of calories. But they may be eaten in smaller quantities than lower-fat foods containing fewer calories. This might suggest that a tax on calorie consumption would be appropriate. Of course, there would be immense practical difficulties with such a tax, since we do not, and cannot conceivably hope to, observe the exact number of calories being eaten per person per day - the problems with implementing a tax on the nutritional content of foods, mentioned earlier, would be massively amplified. However, it is possible, as with the nutrients above, to use the NFS data to calculate the number of calories consumed per day across the income distribution and from this to calculate a hypothetical tax burden. In this example, we tax people at the rate of $0.001 \mathrm{p} / \mathrm{kcal}(1 \mathrm{p} / 1000 \mathrm{kcal})$. This is only a first-run example and takes no account of calories burnt, different recommended calorie intakes for men and women, and so on. In an ideal scenario, we may prefer to tax people according to the excess of calories consumed over calories expended each day - though, in any practical sense, this would be impossible. Nevertheless, our hypothetical 'calorie tax' provides some evidence. Figures 10 and 11 show, respectively, the consumption of calories per day across the income distribution and the average tax rate implied by these figures, each with $95 \%$ confidence intervals as before. As ever, the limitations of the NFS data should be borne in mind.

Figure 10. Daily calorie consumption across the income distribution

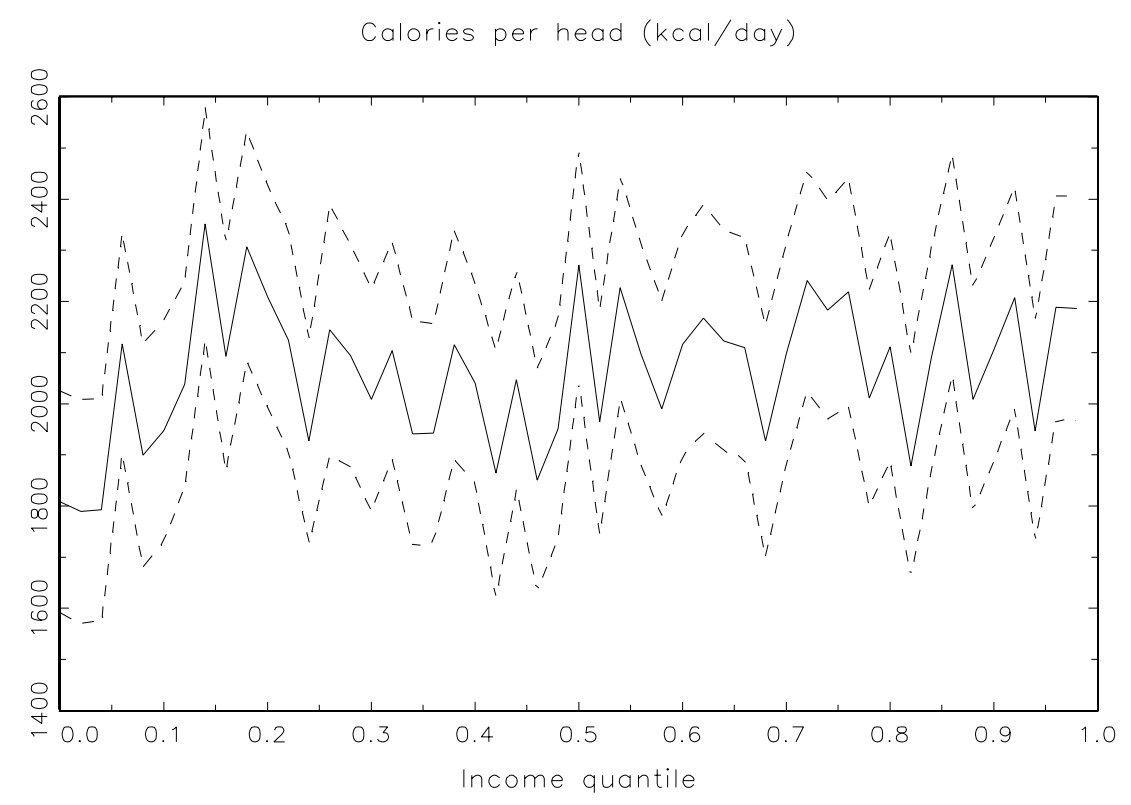

Source: Authors' calculations from the National Food Survey. 
Figure 11. Distributional effects of a 'calorie tax'

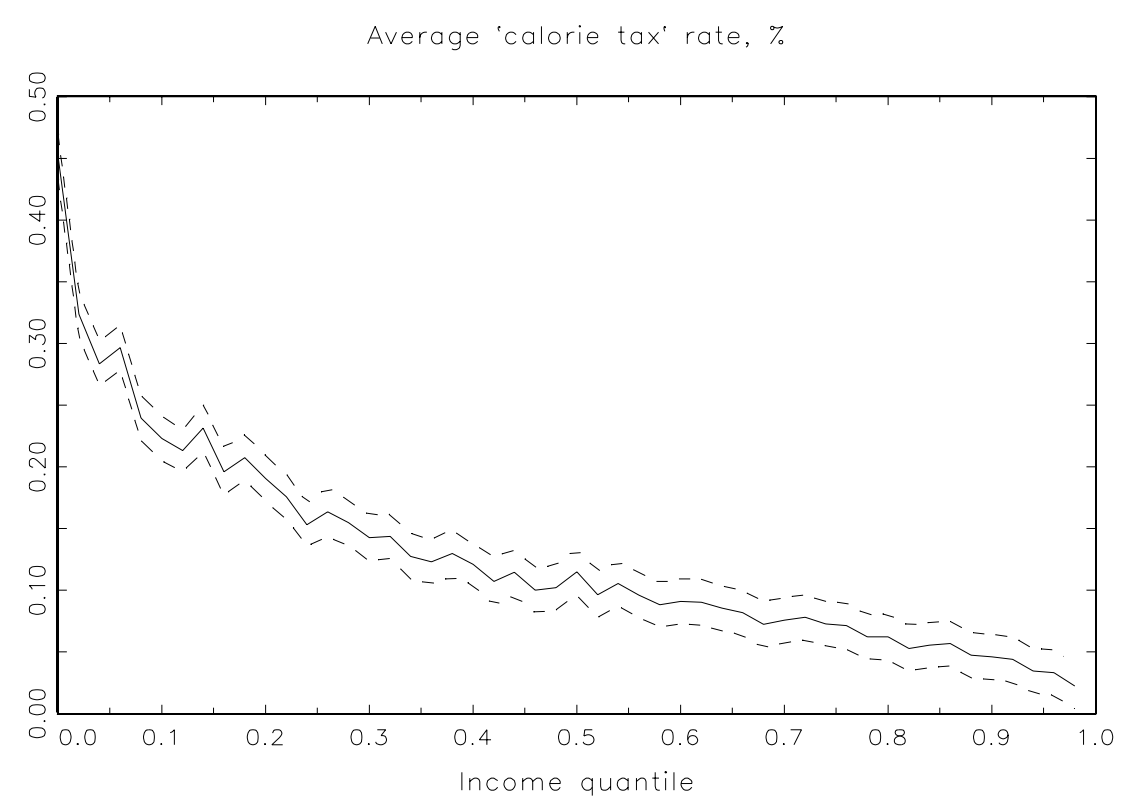

Source: Authors' calculations from the National Food Survey.

As with the individual nutrients, consumption of calories across the income distribution appears fairly flat, which gives us the familiar regressive picture in Figure 11. Here, the poorest people would pay an average tax of just under $0.5 \%$ of their income, slightly less than that implied by the 'fat tax' we examined earlier. The average rate then declines as income increases, at first swiftly and then more gradually, reaching some $0.1 \%$ of income for the median household - again, less than that implied by the 'fat tax' - and somewhat less than $0.05 \%$ of income for the richest.

\section{Conclusions}

Obesity rates have risen substantially in the UK even over the past decade, and forecasts suggest that this trend is likely to continue. A 'fat tax' is one way in which the government might wish to intervene to reverse this trend. We have suggested that a 'fat tax' would probably be regressive, costing the poor relatively more than the rich. This is because consumption of fat and other 'bad' nutrients does not differ much across the income distribution. For the hypothetical tax we model, the poorest households lose around seven times more, as a proportion of income, than the richest households do, on the assumption that there is no behavioural change. The regressivity of a 'fat tax' is likely to hold no matter how the tax is implemented - whether on fat content, on calories or just attached at a particular rate to certain foods.

There is certainly an economic justification for the government to intervene in an attempt to reduce obesity levels, since obesity imposes external costs on society as a whole and some estimates suggest that these costs can be high. A 
'fat tax' is advantageous to the extent that it raises revenue, which the government could then use to finance other measures to combat obesity, such as education programmes or subsidising exercise equipment. However, there would be difficulties and costs in the design and implementation of any 'fat tax', and it may be that the level of taxation necessary to encourage people to change their eating habits would be high. Trials of any 'fat tax' scheme might be desirable in order to assess the potential effects more rigorously, and consultation with the food industry, organisations concerned with obesity, food retailers and the medical profession would be paramount. Monitoring and reevaluation of tax rates and which goods are subject to it would also be important. Assessment of the actual effects, or a pre-assessment of the potential effects, would require more detailed data on food intake and purchasing behaviour (both inside and outside the home) than currently exist.

Given some of the problems highlighted in taxing fat or nutritional content, a more likely policy would perhaps be the taxation of certain foods that are considered unhealthy, such as snack foods or soft drinks. This would be akin to current legislation on alcohol and tobacco, which are also taxed with health concerns in mind. There are limited examples of such schemes in operation around the world at the moment, and some of these raise substantial revenues. It is not clear, however, how much success such a tax would have in reducing obesity levels in the UK. Were it to become largely a source of revenue, public support for it may depend on the funds being seen to be spent on other programmes to help reduce obesity.

\section{References}

Batty, D. (2004), 'Health strategy to take on obesity', The Guardian, 3

February, http://society.guardian.co.uk/publichealth/story/0,11098,1137895,00.html.

Blow, L., Leicester, A. and Oldfield, Z. (2004), Consumption Trends in the UK, 1975-99, London: Institute for Fiscal Studies.

British Heart Foundation (2003), Coronary Heart Disease Statistics 2003, London: BHF Education Department.

Cutler, D., Glaeser, E. and Shapiro, J. (2003), 'Why have Americans become more obese?', National Bureau of Economic Research, Working Paper 9446, http://www.nber.org/papers/w9446.

Department for Transport (2003), Travel to School in GB: Personal Travel Factsheet 2 - January 2003, http://www.dft.gov.uk/stellent/groups/dft transstats/documents/page/dft transs tats_508285.pdf. 
Department of Health (various), Health Survey for England, London: The Stationery Office.

French, S. A., Jeffery, R. W., Story, M., Hannan, P. and Snyder, P. (1997), 'A pricing strategy to promote low-fat snack choices through vending machines', American Journal of Public Health, vol. 87, pp. 849-51.

Gregory, J., Foster, K., Tyler, H. and Wiseman, M. (1990), The Dietary and Nutritional Survey of British Adults, London: HMSO.

Jacobson, M. and Brownell, K. (2000), 'Small taxes on soft drinks and snack foods to promote health', American Journal of Public Health, vol. 90, pp. 8547.

Lechene, V. (2000), 'Income and price elasticities of demand for foods consumed in the home', http://statistics.defra.gov.uk/esg/publications/nfs/2000/Section6.pdf.

Marshall, T. (2000), 'Exploring a fiscal food policy: the case of diet and ischaemic heart disease', British Medical Journal, vol. 320, pp. 301-4.

Meikle, J. (2003), 'Nip'n'tuck on Irish fatties with tax squeeze', The Guardian, 27 August, http://www.guardian.co.uk/guardianpolitics/story/0,3605,1029882,00.html.

National Audit Office (2001), Tackling Obesity in England, London: The Stationery Office.

Prentice, A. M. and Jebb, S. A. (1995), 'Obesity in Britain: gluttony or sloth?', British Medical Journal, vol. 311, pp. 437-9. 